\title{
Spiritual nursing care: A concept analysis
}

Author:
Lydia V. Monareng
Affiliation:
'Department of Health
Studies, University of South
Africa, South Africa
Correspondence to:
Lydia Monareng
Email:
monarlv@unisa.ac.za
Postal address:
PO Box 392, UNISA 0003,
South Africa
Dates:
Received: 28 July 2011
Accepted: 15 June 2012
Published: 08 Oct. 2012
How to cite this article:
Monareng, L.V., 2012,
'Spiritual nursing care: A
concept analysis', Curationis
35(1), Art. \#28, 9 pages.
http://dx.doi.org/10.4102/
curationis.v35i1.28

curationis.v35i1.28
(C) 2012. The Authors. Licensee: AOSIS OpenJournals. This work is licensed under the Creative Commons Attribution License.
Although the concept 'spiritual nursing care' has its roots in the history of the nursing profession, many nurses in practice have difficulty integrating the concept into practice. There is an ongoing debate in the empirical literature about its definition, clarity and application in nursing practice. The study aimed to develop an operational definition of the concept and its application in clinical practice. A qualitative study was conducted to explore and describe how professional nurses render spiritual nursing care. A purposive sampling method was used to recruit the sample. Individual and focus group interviews were audio-taped and transcribed verbatim. Trustworthiness was ensured through strategies of truth value, applicability, consistency and neutrality. Data were analysed using the NUD*IST power version 4 software, constant comparison, open, axial and selective coding. Tech's eight steps of analysis were also used, which led to the emergence of themes, categories and sub-categories. Concept analysis was conducted through a comprehensive literature review and as a result 'caring presence' was identified as the core variable from which all the other characteristics of spiritual nursing care arise. An operational definition of spiritual nursing care based on the findings was that humane care is demonstrated by showing caring presence, respect and concern for meeting the needs not only of the body and mind of patients, but also their spiritual needs of hope and meaning in the midst of health crisis, which demand equal attention for optimal care from both religious and nonreligious nurses.

\section{Introduction}

The ability of nurses to render spiritual nursing care to meet patients' spiritual needs depends on a sound understanding of what is meant by these terms. However, an important obstacle to nursing research and practice in the area of spiritual nursing care has been the lack of conceptual clarity of the concepts of 'spiritual', 'spirituality' and 'spiritual nursing care' (Narayanasamy 2004). There is still evidence of a prevailing conceptual disparity, and vagueness and ambiguity in the descriptions authors give for spirituality or spiritual nursing care (Villagomeza 2005). McSherry and Draper (1998:683) conclude that there is little universal consensus about the meaning of these concepts.

According to McEwan (2004), definitions of spiritual nursing care are sparse. Varied themes of spiritual nursing care in the literature represent a variety of world views and the opinions of people from diverse backgrounds. The descriptions of spiritual nursing care in the literature range from general conceptions of a caring presence to religiously orientated interventions such as prayer or reading religious texts in relation to God's will and His healing powers (Narayanasamy \& Owen 2001; Sawatzky \& Pesut 2005). McSherry and Ross (2002) contend that this lack of definition is the greatest dilemma associated with nursing practice and education, and it hampers nurses' efforts to meet their patients' spiritual needs effectively.

The challenge for nursing is to provide a definition of spiritual nursing care that is universal in its approach, taking into account the importance and relevance of the phenomenon in clinical practice, whilst allowing for the uniqueness of individuals and world views (Stranahan 2001, Villagomeza 2005). Empirical literature provides theoretical, conceptual and operational definitions as experienced in various contexts. On the other hand, Draper and McSherry (2002) contend that an adequate conceptual vocabulary of spiritual nursing care already exists in the literature, but that for the concept to be applied in practice seems to be another matter. However, the nature of nursing today and the multi-faith type of the health-care environment makes it difficult for nurses to foster such resolutions in patients' lives.

Walker and Avant (2005) define concept analysis as a means to clarify over-used or vague concepts that are prevalent in clinical practice. It is a reasonable and logical method that has served the development of science in many disciplines over time. Concept analysis of spiritual nursing care is therefore an essential process to assist in revealing its internal structure and 
critical attributes. Although other methods of concept analysis were incorporated during this process, the method espoused by Walker and Avant (2005) primarily served as a plausible framework to guide the concept analysis process for this article.

\section{Aim and purpose of the study}

The concept 'spiritual nursing care' and its usage was identified by consulting available discipline specific literature, related theories, dictionaries, thesauruses and colleagues in the academic and clinical fields. The researcher has observed over the years how patients are treated in a mechanical way with no regard or intention to show concern for their spiritual needs. The aim and purpose of this analysis was therefore to identify the defining attributes, antecedents and consequences of spiritual nursing care and to examine its possible implications for nursing practice, education and research.

\section{Definitions of key concepts}

Existing theories and the literature provide a source of definitions of spiritual nursing care or related concepts that sometimes extend beyond the limits of common linguistic usages. Theoretical definitions and the way that concepts are used in context convey meanings that are related to the domain of the discipline from which the theory comes (Chinn $\&$ Kramer 2008). Although there are varied perspectives on matters of spirituality, this article focuses only on religious and existential perspectives to identify differences and similarities between these points of view (Table 1).

The cited definitions (Table 1) from the religious and existential perspectives provide elements of spiritual nursing care that are similar and some not. What makes the religious perspectives seem incompatible is that many patients consider their Christian faith-based beliefs to be essential for their spiritual health and well-being. The existential perspectives define spiritual nursing care as care that extends to a more universal dimension that connects humans with a higher being, which may not necessarily be God as referred to by the religious perspective. The religious perspective puts emphasis on reliance on devotional opportunities such as prayer, Bible texts or referral to chaplains to have their spiritual needs met. The existential approach suggests that nurses can use person-centered assistance which, through affirmation, can enable humans to make the best use of all their inner personal and spiritual resources in facing and coping with doubts, anxieties and questions which arise in a health care setting. However, elements from both perspectives were useful to suggest usable definitions of the concept in clinical nursing practice (Sawatzky \& Pesut 2005).

Uses of the concept: The focus of this section was to establish the uses of the concept of 'spiritual nursing care' and the core words, 'spiritual', 'spirit', 'spirituality' and 'care'. The concept of 'spiritual nursing care' was identified by consulting dictionaries, a thesaurus, colleagues and discipline-specific literature. These sources helped to find definitions of the concept as currently used. To clarify the concept of spiritual nursing care further, the related concepts of care, spirit, spiritual and spirituality were examined.

Care: The word 'care' is a noun or verb that denotes providing person-centred care which, through affirmation, enables one to make the best use of all one's personal and spiritual resources when facing and coping with the doubts, anxieties and questions which arise in a health-care setting and often accompany ill health and suffering (Collins English Dictionary \& Thesaurus 1995). Kozier, Erb, Berman and Snyder (2004) define care as intentional engagement with activities that assist a patient or client physically and psychologically.

Spirit: The parent word for spiritual is 'spirit' and it is therefore appropriate to analyse this concept. In Greek culture, spirit is opposed to physical and material reality. In Hebrew, spirit is opposed to death, destruction and negative aspects of the law, such as imposition, fear and punishment. Villagomeza (2005) states that spirit (noun) is typically traced to Latin - spiritus; soul, courage, vigour, breath or vital principle. Ruah, the Hebrew word for spirit, translates as wind, breath and exhalation. Hegarty (2007) adds that

TABLE 1: Definitions of spiritual nursing care.

\section{Religious perspective}

An act of supporting the faith needs of a patient, providing devotional opportunities, encouraging denominational connectedness and cooperating in pastoral care (Treloar 2001).

\section{Existential perspective}

An act of providing person-centred assistance which, through affirmation, enables humans to make the best use of all their inner personal and spiritual resources in facing and coping with the doubts, anxieties and questions which arise in a health care setting and often accompany ill health and suffering (Hegarty 2007).

A matter of using simple ways of helping a patient understand better the true meaning and purpose in life by nurturing his faith in the living God; of enlarging his and/or her capacity for love for God, self and others; of supporting and his and/or her capacity for love for God, self and others; of supporting and
furthering his and/or her appreciation of spiritual values as opposed to those furthering his and/or her appreciatior
of material nature (Emblen 1992).

Spiritual nursing care is viewed as listening to the patient express key concerns; praying with the patient; reading favourite portions of religious texts; spending time with the patient or making a referral to a chaplain (O'Brien 2003).

Spirit refers to 'a deeply situated aspect of the soul subject to spiritual change and growth' or '... the very seat of emotion and desire, and the transmission organ by which human beings can contact God, and relate with others, self and the environment' (O'Brien 2003:286).

A way of life, informed by the moral norms of one or more religions, through which the person relates to other persons, the universe, and the transcendent in ways that promote human fulfillment (of self and others) and universal harmony (Cantazaro \& McMullen 2001:222).

A matter of assisting patients, who may be religious or not, to seek answers for their questions about the meaning and purpose of their illness through their own experiences, abilities and resources, and not necessarily a faith in God (Hall 1997).

At its foundational level, spiritual nursing care is viewed as

... a process that begins from a perspective of being with the patient in love and dialogue, which may emerge into therapeutically oriented interventions that take the direction from the patient's religious or spiritual reality" (Sawatzky \& Pesut 2005:23).

'Spirit' is nevertheless used to refer to a characteristic that is inherent in human nature, namely an inner-state-of-being, rather than immaterial beings or substances beyond the self. Aurelius (1964) as cited by McEwan (2004:322) states that: 'Nowhere can man find a quieter or more untroubled retreat than in his own soul.'

A universal human phenomenon that recognises the wholeness of individuals and their connectedness to a higher being, whether it is God or other; as well as the integrative factor in the quest for meaning in life (Cavendish et al. 2004).

A universal experience that encompasses the whole existential domain and the very essence of what it means to be human (Narayanasamy 2002:949) 
despite different names or definitions given to 'spirit', it is a deep, inner resource from which people can draw strength, especially during difficult times or when faced with lifelimiting illness or death.

Spiritual: In classical Latin 'spiritual' is defined as breath, wind or air, or 'of breathing, of the spirit' and 'of concerning the church'. 'Spiritual' in old French refers to: 'of or concerning the spirit' especially in a religious context. In modern Western culture a spiritual person would be assumed to be disinterested in material gain or worldly concerns (Villagomeza 2005).

Spirituality: 'Spirituality' is a noun which denotes the essence of people's being and the purpose in being, which permeates how they live, and brings awareness of who and what they are, and what their inner resources are which shape their life journey (Dossey, Keega \& Guzzella 2004). It is a personal quest for understanding answers to ultimate questions about life, about meaning and about relationships that are sacred or transcendent (Koenig, McCullough \& Larson 2001).

Spiritual nursing care: At its foundational level, 'spiritual nursing care' is defined as '... a process that begins from a perspective of being with the patient in love and dialogue, which may emerge into therapeutically oriented interventions that take the direction from the patient's religious or spiritual reality' (Sawatzky \& Pesut 2005). There are definitions that depict spiritual nursing care as holistic care which enables the recipients of care to search for meaning and purpose. Spiritual nursing care is also defined as that care that is embodied in the nurse's respect for patient's dignity, display of unconditional acceptance and love, honest nurse-patient relationship, and the fostering of hope and peace' (Sawatzky \& Pesut 2005).

Taylor (2002), on the other hand, defines 'spiritual nursing care' as activities that facilitate a healthy balance between the bio-psychosocial and spiritual aspects of the person, thus promoting a sense of wholeness and well-being. Earlier studies by Van Dover and Bacon (2001) defined spiritual nursing as care engaged in by identifying spiritual needs and concerns of patients and their families and responding promptly and appropriately based on careful assessment of each situation.

\section{Defining attributes of spiritual nursing care}

Walker and Avant (2005) explain that defining attributes are the characteristics of the concept that appear repeatedly in the literature. The defining attributes of spiritual nursing care have been identified from literature as spiritual caring presence, search for meaning and purpose, spiritual dialogue, transcendence and connectedness (Figure 1).

The defining attributes of spiritual nursing are spiritual caring presence, with the related guiding values of search for meaning and purpose, spiritual dialogue, transcendence and harmonious connectedness. Caring presence was identified from data analysis as the core variable from which all the other characteristics emerged. It is defined as a central phenomenon that is used to integrate all other variables (Coyle 2001; Frankl 2004; Polit \& Beck 2008; Villagomeza 2005). Each attribute was described in relation to the empirical referents as manifested by the nurse for further clarity or understanding of how the concept exists in nursing practice. The referents were obtained from the study findings through the use of constant comparative analysis and coding. These attributes are congruent with the worldview of the author and are consistent with related concepts identified in the literature (Figure 2).

It is through the caring presence of the nurse that the values underlying spiritual nursing care are lived out, as exemplified in the model case.

The data analysis identified several defining attributes of spiritual nursing care and their corresponding empirical referents as manifested by nurses in clinical practice (Table 2).

\section{Defining attributes}

When all of the five defining attributes are manifested by the actions of the nurse, this describes a scene of spiritual nursing care as would be depicted in the model case.

Caring presence: This encompasses the concepts of being available, listening, touching and providing spiritual support (Kliewer 2004). It is through this caring presence that the values of compassion, empathy, respect, concern and hope are made visible, as exhibited in Figure 2 (Touhy, Brown \& Smith 2005).

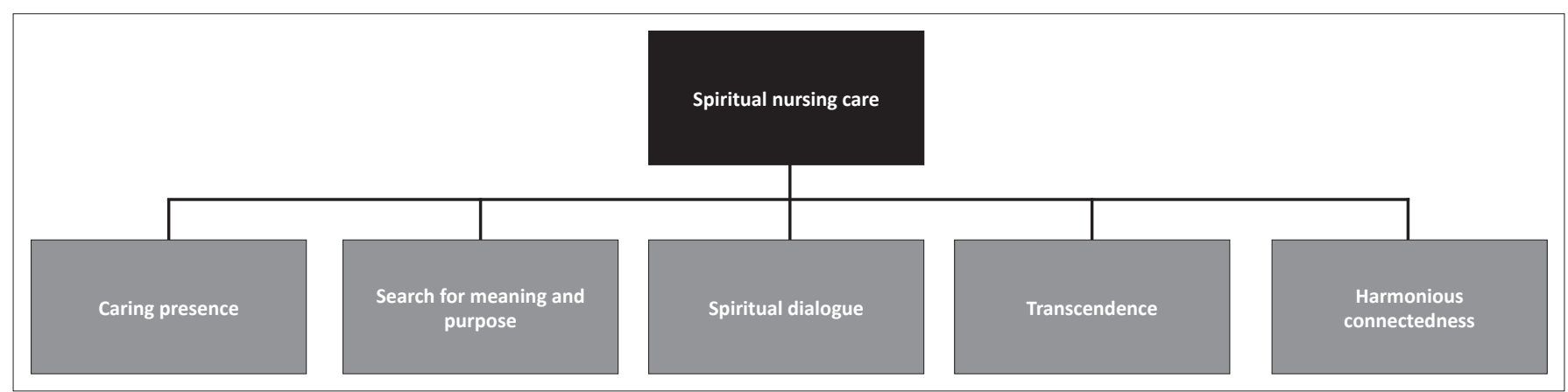

FIGURE 1: Defining attributes of spiritual nursing care. 


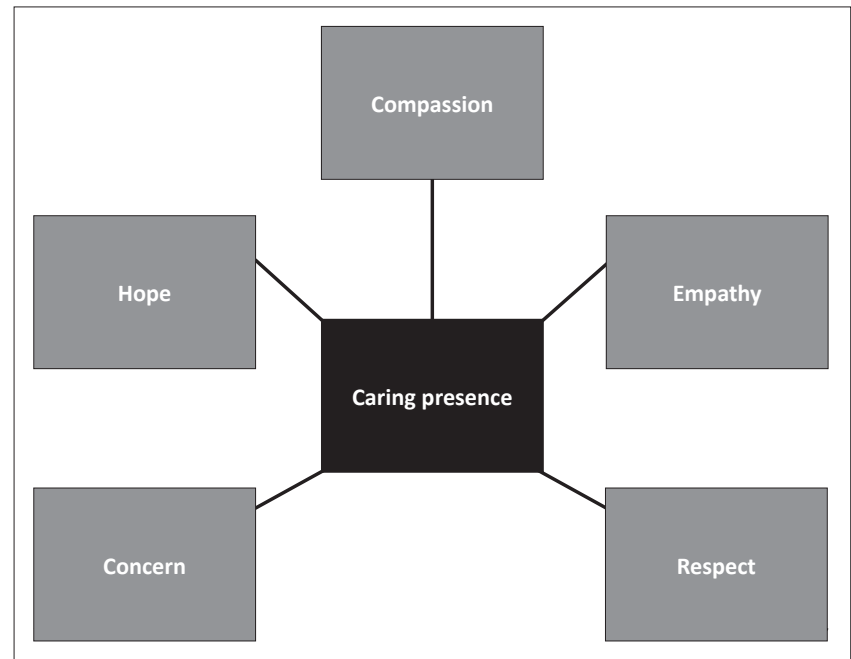

FIGURE 2: Values associated with caring presence.

TABLE 2: Defining attributes and empirical referents of spiritual nursing care.

\begin{tabular}{|c|c|}
\hline Constructs of spiritual nursing care & $\begin{array}{l}\text { Nurses' manifestation of actions of care in } \\
\text { clinical practice }\end{array}$ \\
\hline \multirow[t]{3}{*}{ Caring presence } & - Being truly present with a person who is suffering \\
\hline & $\begin{array}{l}\text { - Provide care guided by values such as } \\
\text { compassion, empathy, care, respect, concern } \\
\text { and giving hope }\end{array}$ \\
\hline & $\begin{array}{l}\text { - Demonstrate ability to help patients deal with } \\
\text { spiritual pain, distress, guilt and even death }\end{array}$ \\
\hline \multirow[t]{2}{*}{ Search for meaning and purpose } & $\begin{array}{l}\text { - Encourage expression of fears and questions } \\
\text { such as 'Why me?' }\end{array}$ \\
\hline & - Focus on the ontological significance of life \\
\hline \multirow[t]{3}{*}{ Spiritual dialogue } & - Use of spiritual language \\
\hline & $\begin{array}{l}\text { - Provide honest answers to spiritually related } \\
\text { questions }\end{array}$ \\
\hline & $\begin{array}{l}\text { - Engage in dialogue by talking with, listening } \\
\text { closely, touching and affirming eye contact }\end{array}$ \\
\hline \multirow[t]{3}{*}{ Transcendence } & $\begin{array}{l}\text { - Provide a quiet space to meditate, reflect } \\
\text { or pray }\end{array}$ \\
\hline & $\begin{array}{l}\text { - Promote connection with possibilities and } \\
\text { realities beyond the self }\end{array}$ \\
\hline & $\begin{array}{l}\text { - Guidance on prayer, meditation and use of } \\
\text { sacred texts }\end{array}$ \\
\hline \multirow[t]{4}{*}{ Harmonious connectedness } & $\begin{array}{l}\text { - Promote healthy spiritual relations with God, } \\
\text { the self, nurses, family, other patients and the } \\
\text { environment }\end{array}$ \\
\hline & - Forgiveness of the self and others \\
\hline & - Promote feelings of spiritual belonging \\
\hline & - Encourage denominational connectedness \\
\hline
\end{tabular}

Search for meaning and purpose: This focuses on the ontological significance of life, which makes sense of life situations and finds purpose in human existence (Villagomeza 2005). Hall (1997) argues from an existentialistic point of view that nurses who render spiritual nursing care assist their patients, who may be religious or not, to seek answers to their questions about the meaning and purpose of their illness or suffering.

Transcendence: This is a process of going beyond our current limitations and gaining a wider perspective of the self and the universe. For human beings, transcendence is part of how the world is experienced (Armstrong 2008). Spiritual caregivers, as is the case in this study, experience the grace that allows them to be aware of the infinite consciousness of God's help for both themselves and their patients in times of suffering. In this relationship, patients become aware of a higher source of power, help, solace and intervention through faith. It is demonstrated by the use of transcendent strategies such as prayer and devotional readings (Touhy et al. 2005).

On the other hand, self-transcendence is experienced as growth into one's unfulfilled potential. It is the process of extending oneself both inwardly in introspective activities and outwardly in relationships with others. Selftranscendence means to be able to reach out beyond oneself, to encounter a higher being, or other human beings, to fulfil meaning and purpose (Skalla \& McCoy 2006).

Spiritual nursing care entails engaging in spiritual dialogue with patients who are experiencing spiritual distress. Dialogue means a conversation between people, or a discussion between representatives of two groups, or exchange of proposals (Concise Oxford Dictionary 1983). Dialectic means a disputation or debate between two people or parties that aim to resolve differences between two views at a higher level of truth. Dialogue can be viewed as a stream of meanings that are expressed between two people engaged in a discussion as a result of which new understandings on spiritual matters emerge. Tanyi et al. (2006) are of the opinion that when patients desire to engage in spiritual dialogue, nurses should be encouraged to feel comfortable with addressing the topic, irrespective of religious orientation.

However, the health-care scene is dominated by staff members and patients who subscribe to varied philosophies and perspectives. A dialogue occurs between these perspectives. Proponents of the secularist philosophy reject religion and believe that it should have no place in the health-care environment. Human beings must not be bound by religious vows of any order (Collins English Dictionary and Thesaurus 1995). The existential view asserts that an individual is seen as a free agent that has its own existence, freedom and ability to make choices in a deterministic and seemingly meaningless universe. People must find their own way to truth or moral perfection without the aid of universal ideas or guidance (Collins English Dictionary and Thesaurus 1995). The phenomenologists assert that the structure of one's experience of or about an object is directed by virtue of its content or meaning. Experiences are perceived as an occurrence or fact by the senses (Collins English Dictionary and Thesaurus 1995).The theistic perspective (Godly spirituality) refers to a possible dialogue between humans and God. Although there are pluralistic views of belief, most health-care workers in South Africa subscribe to Christian traditions and values. Nursing itself, with the historical heritage of Christian values, makes it probable for nursing care to be delivered from a value position characteristic of this heritage (Narayanasamy \& Owens 2001).

Harmonious interconnectedness: This is manifested in healthy relationships with God, the self, others and the environment. Harmonious interconnectedness based on giving and receiving love, and forgiveness brings about meaning and fulfilment to life and provides a purpose for 
living in the face of challenges (Coyle 2001). Connectedness with the environment provides an individual with a means to become immersed in and make sense of the beauty, power and gentleness of nature (Hegarty 2007).

\section{A model case for spiritual nursing care}

Nurse A works in a neurological unit taking care of John, a middle-aged man, who was involved in a car accident which occurred because he drove under the influence of alcohol. Nurse A is committed to expressing love, hope, kindness and compassionate care to her patients. She seeks to respect their beliefs and values, and still be able to attend to their spiritual needs in a competent manner.

On a given day, Nurse A attends to John and observes that he appears to be restless and anxious in spite of all the physical and medical care he is receiving. She makes John comfortable and gives him a cup of warm milk. John shares his feelings of guilt about his life style of drinking, and his fears and frustrations surrounding his injuries. 'Maybe this is how God tries to talk to me or punish me for my sins ...' The nurse explains to John that God loves and cares about him. The nurse sets aside some time to sit at his bedside to talk with him. She touches his hand as a supportive gesture and encourages him to talk. She listens attentively without interrupting him. John responds: 'I appreciate the fact that you took time to listen to me sincerely, talk to me and answer my questions. I feel much better after this conversation'. Nurse A answers John: 'John, life is full of struggles, pain and suffering of different kinds for all of us, but through it all we learn to rely on God's love and care in our trying circumstances through our faith in Him'.

He also confides to the nurse about the impact this situation has on his life, family, job and beliefs. Nurse A answers: 'God is always willing and ready to forgive us our wrongs so that we can forgive ourselves and others who might have wronged us'.

Nurse A makes a commitment to continue the discussion and pray with John when he is ready to do so. John clearly experiences impairment in a sense of disconnectedness (with himself, others and God). Nurse A demonstrates the ability to be available, listen empathetically and talk with John about the spiritual issues which he raises. She also takes a deliberate action to answer his spiritually related questions. She refrains from imposing her religious orientation on him but acts on a cue from him that he is trying to relate his circumstances with a lesson from God.

Therefore, the above model case is an exemplar that includes all the critical attributes identified by the author. These are the caring presence of the nurse, the search for meaning and purpose, spiritual dialogue, transcendence with the divine and harmonious interconnectedness with God, the self, others and the environment. The attributes clearly illustrate the concept of spiritual nursing care.

\section{Related case}

Referring to the model case involving John, Nurse B is doing her normal ward rounds and observes that John is restless and anxious. She finishes her ward rounds and returns to John's bedside. She enquires about what is bothering him. John shares his feelings of guilt about his life style of drinking, and his fears and frustrations surrounding his injuries. 'Maybe this is how God tries to talk to me or punishes me for my sins ...'

Nurse B realises that the patient has spiritual needs beside the physical needs but feels inadequate and uncomfortable to do anything about it. She then calls a pastoral counsellor to come and listen to his story and help him. The nurse then leaves and continues with her other duties. The pastoral counsellor arrives four hours later because he has been busy in other units. Already John is distraught and withdrawn. He talks to John about God's love and power to help him and arranges further visits in the unit.

In this related case, although the nurse engaged in dialogue with the patient, most of the main attributes of spiritual care are missing, for example the nurse's follow-up visit to the patient to provide reassurance.

\section{Contrary case}

Referring to the model case involving John, Nurse C is known to be hard working and has little time to talk to patients about spiritual matters. She describes herself as very busy and believes that nurses should not waste time talking to patients, especially about spiritual matters. In her opinion, spiritual matters should be attended to in a church and not a hospital. Nurse $C$ considers herself to be trained to render nursing care and not spiritual care. On this particular day a student nurse reports to Nurse $C$ that John appears restless and anxious in spite of the analgesic he was given. Nurse C checks John's profile on the computer in terms of his vital signs and prescribes additional medication for pain without seeing the patient. She then instructs the student nurse to administer the additional pain medication and attend to his positioning. John, however, continues to appear anxious and restless despite the additional pain medication. Nurse C comes to his bedside and John says 'Maybe this is how God tries to talk to me because my reckless living has to come to a halt somehow'. Nurse C does not respond to this remark and remains flat in attitude and spiritless. John continues to ask 'You know, nurse, I feel guilty and ashamed about how I have conducted myself and treated my family. Do you think God and my family will forgive me?' Nurse C answers John, 'I don't believe that God has anything to do with your circumstances. You made some bad choices and your present circumstances are the consequences of those choices.' Nurse C informs John that she will ask the doctor to prescribe stronger sedatives and that this will make him feel much better. She then calls the doctor to come and 'see the patient in bed number four' who is very restless and demanding. The doctor complies and Nurse C commences with administering the sedatives. She does not return to talk 
to John. John subsequently becomes withdrawn and does not give any further indication of his spiritual needs. Nurse $C$ then reports that the sedatives are effective because John appears to be relaxed.

Denotations or connotations that make the scenario contrary were the flat, spiritless attitude of the nurse of not showing concern for spiritual needs of the patient. The nurse had little or no time to talk to the patient and prescribed medication without even seeing the patient, which demonstrated absence of a caring presence. The belief of the nurse that nurses should not waste time talking to patients on spiritual matters as this is a hospital and not a church cuts off the patient from sharing his feelings. The patient could not have his questions related to a search for meaning and purpose answered. The answer that a nurse is trained to render nursing care and give medications, which obviously are meeting physical needs only and not those of a spiritual nature, showed spiritual incompetency.

\section{Antecedents and consequences of spiritual nursing care}

Antecedents are those events or incidents that must occur prior to the occurrence of the concept (Walker \& Avant 2005). The events or incidents that support the need for spiritual nursing care must occur before such care can be given. Analysis of literature reviewed suggested the following as antecedents of spiritual nursing care:

- Spiritual discomfort requires the rendering of spiritual nursing care to patients who have to cope with illness, disease or injury and who express spiritual distress or spiritual pain that is beyond physical treatment (Alvin et al. 2007).

- Self-awareness of the nurse is a prerequisite because nurses need knowledge of their own spiritual world view and that of the patient, as well as associated biases to be able to develop the ability to handle the spiritual needs of those under their care (Sawatzky \& Pesut 2005).

- Transcendent awareness of the nurse entails understanding by the nurse that people have the ability to make meaning of their circumstances if appropriately supported. They are able to reach beyond themselves to spiritual sources that enable them to be at peace with their situation (Sawatzky \& Pesut 2005).

- Spiritual sensitivity that enables nurses to identify the patients' spiritual needs accurately, recognise the presence of spiritual distress and render spiritual nursing care at the right moment without imposing their views and beliefs on the patient (Sawatzky \& Pesut 2005).

- Caring presence disposition of the nurse is a needed antecedent. According to Hegarty (2007), it is a state of being truly present alongside the patient for support and care, to stay there even when there are no easy solutions or answers to questions. It becomes easy to incorporate into the day-to-day nursing practice an attentive and reflective approach to develop abilities and skills in that area (Hegarty 2007).

- Trusting relationship is also an important antecedent so that patients may view the nurse as honest, open and concerned about their welfare (Kozier, Erb \& Wilkinson 2008).
- Spiritual competency is essential because nurses require the necessary knowledge, skills, insight and confidence to handle the different phases of the nursing process and contextual conditions for providing spiritual nursing care (Villagomeza 2005).

Consequences are events and conditions that occur as a result of the concept having occurred (Villagomeza 2005). Consequences are useful in determining frequently neglected ideas, variables or relationships that may yield fruitful new research questions and directions, hypotheses and theory development (Meraviglia 1999). Positive outcomes of the occurrence of nursing care that were identified in the literature were spiritual integrity, a heightened sense of wellbeing and spiritual health:

- Spiritual integrity is present as an outcome when a person experiences wholeness within the self, with other human beings and in transcendence with God (Labun 1988). Wholeness within the self, as explained by O'Brien (2003), refers to being closely attuned to the body, mind and spirit connection.

- A heightened sense of wellbeing is characterised by specific outcomes such as spiritual wellbeing and spiritual health. Spiritual wellbeing is an affirmation of life in a relationship with God, the self, others, the community and the environment that nurtures and celebrates wholeness. People who enjoy spiritual wellbeing tend to feel alive, purposeful and fulfilled (Labun 1988).

- Spiritual health is present when a person is in a state of well-being and equilibrium in that part of his or her essence and existence which transcends the realm of the natural (O’Brien 2002).

Although antecedents and outcomes are often dealt with in passing in concept analysis, they do shed considerable light on the social contexts in which the concept is generally used. However, at this point, the identified outcomes are still theoretical assumptions that emerge from both qualitative and quantitative studies. There is still a need for empirical evidence on the existence of this reality in nursing practice (Zisberg et al. 2007).

\section{Contribution to the field}

Spiritual nursing care is omitted from clinical practice for various reasons. This is a shortcoming that must be dealt with. Nurse clinicians are encouraged to utilise information about the defining attributes of spiritual nursing care and the identified empirical referents (Table 2) for guidance. Empirical referents are defined by Walker and Avant (2005) as indicators that exemplify the existence of the concept itself or validate its existence in clinical practice. An outline of the defining attributes with examples of how they can be evidenced in practice (Table 2). It can also be used as a reference tool to suggest activities or approaches that nurses can employ and record on the nursing care plans when patients present with spiritual needs. Villagomeza (2005) suggests that nurses who are comfortable with providing spiritual nursing care, or possess skills and experience of providing such care, should act as mentors and role models for others in practice and in incorporating such care. 


\section{Research method and design Design}

This study used a qualitative grounded theory research design to explore and describe professional nurses' conceptualisation of spiritual nursing care. The researcher examined data and began to code, categorise, conceptualise and modify data collection according to the emerging theory and asked more penetrating questions as needed (Burns \& Grove 2007:66; Polit\&Beck2008:402). Symbolic interactionism (SI) was used as a philosophical base that guided data collection and analysis. SI, according to Blumer (1989), has three underlying premises. Firstly, that humans act towards things based on the meaning that the things have for them. In this context, spiritual nursing care involves objects such as the nurse herself, religious books, the cross, the Bible or other religious artefacts whose meaning influence the actions of both the nurse and the patient. Secondly, the meaning of things is derived from how people interact with one another. Therefore, meanings are continually created, recreated and modified as care is provided, questions answered and hope and meaning provided for patients by the caring presence of the nurse. Thirdly, meanings are handled through an interpretative process as nurses and patients have an encounter with each other through spiritual dialogue, prayer or singing spiritual songs (Blumer 1969:18-19).

\section{Material}

People involved in the study were the researcher, participants who were registered nurses, and two professors who were experts in qualitative studies.

\section{Data collection methods}

A questionnaire was used to collect demographic data. To collect data, an interview guide with a grand tour question, 'How do you render spiritual nursing care for your patients in your daily practice?' was used to conducted four individual interviews.

A semi structured interview guide was used to conduct four focus group interviews asking the following questions:
'What you understand about spiritual nursing care?'
'How do you provide spiritual nursing care for your patients in your daily practice?'
'Tell me, what do you understand by holistic patient care?'
'Explain to me, how your religious values guide your care and relationship with your patients and their families as a nurse?'
'What challenges or barriers do you experience when providing spiritual nursing care?' (Taylor 2002:28).

Direct observation and field notes were utilised, especially for data collection and analysis triangulation purposes as some of the categories emerged from them. The researcher was the primary data collection instrument because she had to think of the questions during the interview or make observations and other strategies to get a clear view of what participants understood about spiritual nursing care and how they provide spiritual nursing care to patients in clinical practice (Parahoo 2006:69). Entry and access into the research setting was negotiated with the appropriate authorities with permission granted in writing The researcher arranged and communicated the date, time and venues well in advance for both the individual and focus group interviews.

\section{Data analysis}

Volumes of data were gathered and stored in an organised way for easy retrieval. Data was managed by converting the narrative data into smaller more manageable segments as guided by various qualitative research authors. Each audiotaped individual and focus group interview was recorded and transcribed verbatim by the researcher herself shortly after the interviews (Burns \& Grove 2007:79; Polit \& Beck 2008:508515; Streubert-Speziale \& Carpenter 2003:34). Morse's (1996) instructions for transcribing tape-recorded interviews were followed. The transcripts were read and verified against data several days later. The interviewer listened to the tapes objectively as recommended by Morse and Field (1995:131) and critiqued her own interviewing style. Inconsistencies were noted on how questions were asked and improvements were made in subsequent interviews. The transcriptions were then typed and imported into a code based theory builder which is the Qualitative Research Solution's Nonnumerical Unstructured Data way of Indexing, Searching and Theorising computer software, known as NUD*IST power version, revision 4.0 and began with the analysis process. This software assisted the researcher in handling and managing complex non-numerical data (Burns \& Grove 2007:79) with the help of advanced qualitative researchers.

\section{Context of the study}

The study was conducted in an 800-bedded academic hospital in the Gauteng Province in South Africa. The clinical settings where the participants were working included a variety of units such as surgical, medical, paediatric, orthopaedic, ICU, HIV and AIDS clinic and gynaecological units in the hospital where both acute and chronically ill patients were cared for, as well as the outpatients' department thereof.

\section{Results}

The findings revealed a neglect of the patients' spiritual needs due to the carer's ignorance and inability to recognise manifestations of spiritual needs or symbolic requests for spiritual care, which was noted as damaging to achieving quality total patient care. Commonly, treatment in health care environments is identified with physical or medical treatment in terms of tablets or injections as illustrated in the following comment:

'... God in us as a spiritual being of us, and that part cannot be touched by tablets, cannot be touched by EHM! Cannot be touched by injections or whatever we use to heal a person, so the spirit needs the spirit'.

Intangible needs have frequently been given a much lower priority than needs which were more obvious and more easily measurable. Showing concern for patients was coupled with the value of love for patients: 
'... the other thing that you can do just to meet the spiritual needs of the patient, is ... going to be ... where one shows love for the patient or shows concern to the patient'.

Nursing as a profession is more concerned about implementation of principles, policies, protocols and other professional acts, but this finding brings to light that showing love and concern for patients is part of the treatment given to patients for holistic care. Participants indicated lack of guidelines during the basic training years on how to provide such care:

'I think it also lies within the individual how to carry the spiritual care, how to carry [out] the spiritual care. It wasn't guidelined or it wasn't given the principles during training'.

This finding was supported extensively in literature.

\section{Ethical considerations}

The rights of the participants were protected in this study by obtaining informed consent, as participants were given full information about the study, as to what its requirements, purpose and benefits were. Respect for confidentiality and anonymity was maintained by ensuring that private information given about or by the participants was not divulged to unauthorised others without the participant's knowledge (Burns \& Grove 2007:531; Polit \& Beck 2008:747). Protecting the right to withdraw from the study was enforced by informing the participants that they could refuse to participate or withdraw after signing the consent form or at any time during the research process without penalty.

Respect for human dignity was shown by how questions were posed and the participants were allowed to express themselves fully without interruption unless where necessary. Difficult questions were rephrased and made simpler for the participants to respond to without feeling humiliated. Privacy was maintained during the individual interviews by conducting interviews in the participants' homes. Focus groups were also held in an office designated for the interviews. A 'Do not disturb' notice was placed at the door to avoid exposing the participants. Their religious views, opinions and beliefs were not divulged to unauthorised persons.

\section{Trustworthiness}

Lincoln and Guba (1985:291-292) developed a model for assessing qualitative data in terms of its trustworthiness using four criteria according to which the information is evaluated for credibility, applicability, consistency and neutrality (Krefting 1991:215; Streubert-Speziale 2003:133).

Credibility was maintained through prolonged engagement. During data collection the researcher spent an extended period of time with the participants whilst she conducted unstructured and semi-structured interviews. The participants were allowed to verbalise their feelings without being hurried or interrupted. Questions in some instances were repeated for more clarity. The interviews were conducted until data saturation. During data analysis, tape recordings were listened to over and over again, transcripts were written and re-written, read and re-read to understand the data obtained. Following analysis, interpretations were taken backwards and forwards to some of the participants for validation. The researcher therefore immersed herself in the data from the time data collection commenced to completion of this report.

Applicability was ensured by providing detailed descriptions of the research design and methodology for possible application of the study in other settings. The thick descriptions continued in tapes, transcripts, observations and field notes which were presented for use by other researchers.

Consistency was made possible by establishing an audit trail, which was a detailed report on the exact method of data gathering, context of the interviews, data analysis and interpretation. Data obtained from the interviews were coded and checked by two advanced qualitative researchers. Results were then compared and any differences in themes, categories and subcategories were noted (Krefting 1991:221). Neutrality was established through employment of an audit trail.

\section{Discussion}

The conceptualisation of spiritual nursing care in this concept analysis generated information that needs to be further explored in practice for its contribution in improving quality of health. McSherry, Cash and Ross (2004) explain that providing holistic patient care is attending to all the dimensions of patient care with equal significance. However, in reality, the spiritual dimension of this care remains abstract and subjective. The empirical referents outlined (Table 2) provide examples of ideas on what actions nurses can engage in to provide holistic patient care. Allvin, Berg, Idvalln and Nilson (2007) highlight that in some instances the empirical referents provide the rationale for the identified attributes. It is hoped that although there are many complex issues around this phenomenon, this short concept analysis can be used as guidance towards clarity as to what spiritual nursing care entails. Nurse clinicians can also develop nursing care plans that incorporate spiritual nursing care-related interventions that will make a clinical difference (McBrien 2006).

\section{Limitations of the study}

Although this contextual research study yielded in-depth insight into various aspects of spiritual nursing care, some people may criticise it for a lack of generalisability of its findings because of the sample size. Use of convenient samples also could have affected the ability to maintain neutrality because participants were known to the researcher and they could have biased the findings by giving responses to impress the investigator. The researcher's experience and subjectivity could have biased the findings in the interpretation of findings. Further research using the quantitative paradigm would provide more meaningful findings to enhance spiritual nursing care in clinical practice. 


\section{Conclusion}

Conducting the concept analysis was a valuable intellectual exercise and it actually formed a basis for the literature review for the study. Identification of the concept and familiarity with the literature had an impact on how the process was begun and followed through. Although various methods of concept analysis were explored, Walker and Avant's (2005) method was employed to structure a strategy to analyse the concept 'spiritual nursing care'. The steps in this analysis included identifying the concept, stating the purpose of analysis, theoretical definitions, and uses of the concept, determining and defining the attributes of the concept and presenting the model, related and contrary cases. The antecedents and consequences of the concept were described briefly. Therefore a suggested operational definition of spiritual nursing care based on the findings was that 'humane care is demonstrated by showing caring presence, respect and concern for meeting the needs not only of the body and mind of patients, but also their spiritual needs, which demand equal attention for optimal care from both religious and nonreligious nurses. The paper concludes with a table summarising the attributes and referents of the concept, to attempt to identify its relevance in clinical practice (Table 2).

\section{Acknowledgements}

I acknowledge God Almighty for giving me the grace to conduct this study. The continual help and empirical guidance of Professors S.M. Mogotlane, L. de Villiers and V. Ehlers was valuable. I acknowledge with gratitude Mrs Rina Coetzer for formatting the document and Mrs Carol Jansen for editing it. I am grateful to the George Mukhari Hospital management for granting me permission to conduct the study in their hospital and all the participants. I also acknowledge my family and late mother for their support and prayers.

\section{Competing interests}

The author declares that there are no financial or personal relationships which have inappropriately influenced the author to publish this article.

\section{References}

Alvin, R., Berg, K., Idvall, E. \& Nilson, U., 2007, 'Postoperative recovery: A concept analysis', Journal of Advanced Nursing 57(5), 552-558. http://dx.doi.org/10.1111/ j.1365-2648.2006.04156.x, PMid:17284272

Armstrong, K., 2008, What is transcendence? viewed 29 June 2008, from http://www. selftranscendence.org/self_transcendance/what is self transcendence/

Chinn, P.L. \& Kramer, M.K., 2008, Theory and nursing: Integrated knowledge development, 7th edn., Mosby Year Book, St Louis.

Collins English Dictionary and Thesaurus, 1995, 3rd edn., Harper Collins, New York.

Coyle, J., 2001, 'Spirituality and health: Towards a framework for exploring the relationship between spirituality and health', Journal of Advanced Nursing 37(6) 589-597. http://dx.doi.org/10.1046/j.1365-2648.2002.02133.x, PMid:11879423

Dossey, B.M., Keegan, L. \& Guzzella, C.E., 2000, Holistic nursing: A handbook for practice, 4th edn., Aspen, New York.

Draper, P. \& McSherry, W., 2002, 'A critical view of spirituality and spiritual assessment', Journal of Advanced Nursing 39(1), 1-2. http://dx.doi.org/10.1046/j.13652648.2002.02285.x, PMid:12074745

Frankl, V.E., 2004, Man's search for meaning, 2nd edn., Rider, Johannesburg.
Govier, I., 2000, 'Spiritual care in nursing: A systematic approach', Nursing Standard 12(14), 32-36

Hegarty, M., 2007, 'Care of the spirit that transcends, religious, ideological and philosophical boundaries', Indian Journal of Palliative Care 13(2), 4247. http:// dx.doi.org/10.4103/0973-1075.38898

Kliewer, S., 2004, 'Allowing spirituality into the healing process', The Journal of Family Practice 53(8), 616-624. PMid:15298831

Koenig, H.G., McCullough, M.E. \& Larson, D.B., 2001, Handbook of religion and health, London, Oxford University Press. http://dx.doi.org/10.1093/acprof:o so/9780195118667.001.0001

Kozier, B., Erb, G., Berman, A. \& Snyder, S., 2004, Fundamentals of nursing: Concepts, process and practice, 7th edn., Prentice Hall, Sydney.

Krefting, L., 1991, 'Rigor in qualitative research: The assessment of trustworthiness', American Journal of Occupational Therapy 45(3), 214-222.

McBrien, B., 2006, 'A concept analysis of spirituality', British Journal of Nursing 15(1), 42-45. PMid: 16415748

McEwan, W., 2004, 'Spirituality in nursing', Orthopaedic Nursing 23(5), 321-326. http://dx.doi.org/10.1097/00006416-200409000-00008, PMid:15554469

McSherry, W. \& Ross, L., 2002, 'Dilemmas of spiritual assessment: Considerations for nursing practice', Journal of Advanced Nursing 38(5), 479-488. http://dx.doi. org/10.1046/j.1365-2648.2002.02209.x, PMid:12028281

McSherry, W., Cash, K. \& Ross, L., 2004, 'Meaning of spirituality: Implications for nursing practice', Journal of Clinical Nursing 13, 934-941. http://dx.doi. org/10.1111/j.1365-2702.2004.01006.x, PMid:15533099

McSherry, W. \& Draper, P., 1998, 'The debates emerging from the literature surrounding the concept of spirituality as applied to nursing', Journal of Advanced surrounding the concept of spirituality as applied to nursing', Journal of Advanced Nursing 27(4),
PMid:9578196

McSherry, W. \& Ross, L., 2002, 'Dilemmas of spiritual assessment: Consideration or nursing practice', Journal of Advanced Nursing 38(5), 479-488. http://dx.doi. org/10.1046/j.1365-2648.2002.02209.x, PMid:12028281

Meraviglia, M., 1999, 'Critical analysis of spirituality and its empirical indicators: Prayer and meaning in life', Journal of Holistic Nursing 17, 18-33. http://dx.doi. org/10.1177/089801019901700103, PMid:10373840

Morse, J.M., 1996, Nursing research - The application of qualitative approaches, 2nd edn., London, Chapman \& Hall.

Narayanasamy, A. \& Owens, J., 2001, 'A critical incident study of nurses' responses to the spiritual needs of their patients', Journal of Advanced Nursing 33(4), 446-455. $\mathrm{http}: / / \mathrm{dx}$.doi.org/10.1046/j.1365-2648.2001.01690.x, PMid:11251732

Narayanasamy, A., 2004, 'The puzzle of spirituality for nursing: A guide to practical assessment', British Journal of Nursing 13(19), 1140-1145, PMid:15573007

O'Brien, M.E., 2002, Spirituality in nursing: Standing on holy ground, 2nd edn., Jones \& Bartlett, Boston

Polit, D.F. \& Beck, C.T., 2008, Nursing research: Generating and assessing evidence for nursing practice, 8th edn., Lippincott Williams \& Wilkins, Philadelphia.

Reed, P.G., 1992, 'An emerging paradigm for the investigation of spirituality in nursing', Research in Nursing and Health 15, 349-357. http://dx.doi.org/10.1002/ nur.4770150505

Sawatzky, R. \& Pesut, B., 2005, 'Attributes of spiritual care in nursing practice', Journal of Holistic Nursing 23(1), 19-33. http://dx.doi.org/10.1177/0898010104272010, PMid:15665264

Skalla, K.A., 2006, 'Spiritual assessment of patients with cancer: The moral authority, vocational, aesthetic, social and transcendent model', Oncology Nursing Forum 33(4), 745-751. http://dx.doi.org/10.1188/06.ONF.745-751, PMid:16858455

Stranahan, S., 2001, 'Spiritual perception, attitudes about spiritual care and spiritual care practices among nurse practitioners', Western Journal of Nursing Research 23(1), 90-104. http://dx.doi.org/10.1177/01939450122044970, PMid:11216028

Streubert-Speziale, H.J. \& Carpenter, D.R., 2003, Qualitative research in nursing Advancing the humanistic perspective, 3rd edn., Lippincott, Williams \& Wilkins.

Tanyi, R.A., Recine, A.C.G., Werner, J.S. \& Sperstad, R.A., 2006, 'Perceptions of incorporating spirituality into their care: A phenomenologist study of female patients of haemodialysis', Nephrology Nursing Journal 33(5), 532-538. PMid: 17044437

Taylor, E.J., 2002, Spiritual care: Nursing theory, research and practice, Prentice Hall, Upper Saddle River, New Jersey.

The Concise Oxford Dictionary, 1983, Clarendon Press, Oxford.

Touhy, T.A., Brown, C. \& Smith, C.J., 2005, 'Spiritual caring: end of life in a nursing home', Journal of Gerontological Nursing 27-35. PMid:16190010

Treloar, L.L., 2001, 'Spiritual care: safe, appropriate, ethical', Journal of Christian Nursing 18(2), 16-20.

Van Dover, L. \& Bacon, J.M., 2001, 'Spiritual care in nursing practice: A close-up view', Nursing Forum 36(3), 18-30. http://dx.doi.org/10.1111/j.1744-6198.2001. tb00245.x

Villagomeza, L.R., 2005, 'Spiritual distress in adult cancer patients: Toward conceptual clarity', Holistic Nursing Practice 19(6), 285-294. PMid:16269948

Walker, L.O. \& Avant, K.C., 2005, Strategies for theory construction in nursing, 4th edn., Upper Saddle River, New Jersey, Pearson/Prentice Hall.

Zisberg, A., Young, H.M., Schepp, K. \& Zysberg, L., 2007, 'A concept analysis of routine: Relevance to nursing', Journal of Advanced Nursing 57(4), 442-453. http://dx.doi. org/10.1111/j.1365-2648.2007.04103.x, PMid:17291208 